\title{
DOCUMENTOS
}

\section{Un cuento inédito de Alfonso Reyes}

Aquí reproducimos un cuento inédito de Alfonso Reyes, con el permiso y debido a la gentileza de doña Manuela $M$. de Reyes.

Dentro de las variadas ficciones alfonsinas, este relato participa a la vez del encanto peculiar del cuento-divagación o cuento-ensayo al estilo de "Los estudios y los juegos" o "Antonio duerme" (Quince pre. sencias) y del cuento psicológico o caracterológico al estilo de " $\mathrm{La}$ fe" o "Pasión y muerte de Dona Engraçadinha" (ambos en Quince presencias, y "La fea" también en Verdad y mentira). En el primero de estos tipos suelen interesar por partes iguales el desarrollo central y las escursiones laterales, o bien, como dice Reyes más adelante en "El Samurai": "me temo que la preparación de mi historia te interese más que el desenlace..." En el segundo tipo, el núcleo mínimo del argumento suele interesar menos en sí que el sucesivo despliegue de los matices psicológicos, y la curiosidad y perspicacia del escritor ante los casos de psicología amorosa anima el tenue hilo narrativo para mantener siempre despierto el interés del lector.

Recordamos al mismo tiempo las observaciones de don Alfonso en "La fea":

Necesito cortar constantemente mi narración con desarrollos ideológicos. Yo sería un pésimo novelista. Mucho más que los hechos, me interesan las ideas a que ellos van sirviendo de símbolos o pretextos.

$\mathrm{Y}$ nos quedamos con que este frivolo y serio, erudito don Alfonso - con su don de simpatía y sentido del calor humano, confesando su ausencia de vocación de novelista-exhibe aquí precisamente las cualidades que le consagran como un admirable cuentista. 


\section{EI SAMURAI}

\section{Por Afonso REYES}

Río, 20 de agosto de 1938.

Mi querido Carlos:

Me has hecho creer -halagando ciertamente uno de mis más profundos instintos- que yo soy una naturaleza epistolar, y que de tal manera me ves inculcado en la necesidad de escribir que, si no hubiera papel y pluma, no se explicaría mi paso por la tierra. Así te las has arreglado para que yo te escriba cartas de todas partes a donde voy, aunque tú te olvides de contestarme. Yo sé que eso es lo que quieres, pero te confieso que tal situación corresponde también a mis deseos más intimos. Porque yo tengo - como todo viajero-muy dispersa la vida, y diseminada en tantas tierras cuantas hasta ahora he recorrido; $y$ aunque llevar un diario me serviria para atar los cabos o ensartar en un hilo de tinta las perlas sueltas de mi varia existencia, soy muy perezoso para ese menester, y en cambio me siento singularmente excitado a la sola idea de que estoy escribiendo para los ojos de un amigo. Así, doy unidad a mi ser, tejiendo a punta de pluma sus miembros desconyutados y sueltos, y el escribirte me ayuda a sentir la trayectoria de mis andanzas, que de otra suerte se me perdería en la maraña de comarcas y latitudes.

Cada clima y cada época -por un mimetismo inherente a la humana naturaleza- determinan, en mi modo de ser, alguna variante. $Y$ al llevar registro de mi mismo en las cartas que de todas partes te envio, me sirve para buscar y fijar el tema fundamental de mi ser. ¿No compara Von Vexküll ta vida de todo ser con una melodía? Pues yo soy una melodia arborescente, por la obligación de ramificarme en que me ponen los cauces que recorro; y de aquí que necesite un estudio, unos instantes de concentración, allá de cuando en cuando, para reasirme otra vez $\mathrm{y}$ adueñarme de mi propia conducta. $\mathrm{Y}$ esos instantes son los que consagro a escribirte, dándote mis noticias.

Yo creo, guardando respetuosamente las proporciones, que mi caso se parece al de don Juan Valera quien, como yo, también andaba viajan. do y escribiendo libros. $Y$ me figuto que los millares de cartas de su mano y de que la mayoría, según me ha revelado mi amigo Manuel Azaña, sigue custodiada por la familia, sin que haya modo de obtener licencia para su publicación, lo que es una lástima, le hacían veces; como a mi, de puntos de sutura entre las diversas piezas de su vida. $Y$ también sospecho-y aqui otra utilidad de las cartas-que, siendo comu- 
nicativo $y$ sociable ya de suyo, en lugar de tomar nota de sus recuerdos mediante un solitario monólogo, prefería ir vertiendo en sus cartas cuanto le parecia digno de ocupar su memoria, y luego ojeaba las copias - que siempre conservaba- para ir sacando de ahí el material de sus bien documentadas novelas.

Sea como fuere, has ganado la suerte de tener un amigo que te divierta en tus insomnios. Porque no pongo en duda que mis cartas te sean una diversión y esparcimiento. Me confieso a veces contigo a corazón abierto, y lo que es a ti te cuento cosas que no me las contaría a mí mismo, sin la viciosa provocación de escribitte, que ya va rayando en mania. El día que un doctor psicoanalista de los de ahora me quisiera partear el alma con esa nueva mayéutica a que Freud ha dado su nombre-ya presentida por Sócrates y ya aplicada con empírica sabiduria por la iglesia católica - no iba a encontrarme ningún complejo o, digamos, gato encerrado en la subconsciencia, porque todo lo habré volcado, depurándome de paso a mí propio, en estas mis interminables epistolas.

Pues ¿qué dirás si te traigo ahora a los más escondidos secretos de mis dias y mis noches, como si te pusiera en mi alcoba y detrás de un biombo - nuevo Cardenal de Bernis-a contemplar lo que siempre se hizo a solas y que nuestro padre Rabelais llamaba "jugar a la bestia de dos lomos"?

Anda por ahí un refrán que dice: "Quien quiere la col, quiere las hojitas de alrededor". Pero éste es precisamente la fatalidad del amor, el cual nunca quiere las hojitas y el yerbajo adventicio, sino, como en el poema de Juan Ramón Jiménez, la flor sin tallo y sin raíz, la flor pura. Al amor le estorba todo el cuadro de las convenciones sociales a través de cuya maraña tenemos que desentrañarlo; y como nunca se da en estado de limpidez, sino que aparece tejido con cosas que le son ajenas, aunque el amor en sí sea bueno, meterse en una historia de amor resulta siempre, como dice la gente, meterse en un lío, en un quebradero de cabeza. Por donde todo amor trae consigo enojos sin cuento. El perfecto amante, como el "Don Juan" de Bernard Shaw, siente que su amor se enfría un poco en cuanto descubre, en la mujer que lo atraía, el parecido con los padres o los hermanos, el diente orificado, cualquier rasgo, en suma, que perturba en el objeto amado la perfecta femineidad y su "individua. ción" absoluta. Pues iqué si tiene que cargar, además, con los amigos $y$ amigas, las primas o las tías! Hay que tener resistencia de avestruz para tragar, con el verdadero alimento, una porción de piedras. Te digo esto para que me compadezcas cuando sepas que yo me enamoré de una mu. 
chacha que andaba siempre rodeada de unos cuantos amiguitos, quienes siempre la acompañaron desde la infancia.

Es frecuente que ciertas niñas, en quienes la sensualidad habla pronto, aunque ande como difusa y no localizada, prefieran la amistad de los varoncitos de su edad, y hasta adopten sus juegos y sus vestidos, empujadas por un instinto cuyo verdadero nombre ignoran todavía. $Y$ si toca la casualidad de que los varoncitos que les caen en suerte sean de este tipo equívoco y levemente indefinido, que tanto se da entre la generación juvenil de ahora, entonces se crca entre ellos y ellas una asociación de tipo casi morboso - aun cuando no caigan en cosas ilicitas-, una cohesión secreta y cerrada, un entendimiento tácito; con todos los gustos y picantes de la confabulación contra los demás grupos sociales. El entendimiento llega a lo increíble: todo es, entre ellos, palabras convenidas, guiños, señales indescifrables. iAy del que se deja atraer por un torbellino semejante! iAy del que se deja morder por estas tenazas, y sobre todo si no pertenece a la categoría que, a falta de término más piadoso, he llamado aqui "indefinida"! El que se atreve a romper el círculo mágico, que espere castigos. El que entra en esta masonería secreta ya puede vivir la barba sobre el hombro.

Imaginate, pues, una de estas muchachitas que digo, criada entre muchachos de virilidad indefinida, que la tratan fraternalmente $y$ hasta la respetan a su modo. Entre ella y ellos no había un cambio de experiencias sexuales, sino sólo un comercio de intimas revelaciones y charlas que mantenia alerta la curiosidad y el vago apetito. Graciela se acostumbraba a ser la confidente y a compadecer y entender los desvios de los muchachos. Ellos han encontrado en ella el medio de asociarse a una mujer sin necesidad de amor: es el mínimo de mujer que ellos toleran. Además, a Graciela y a sus amigos les atrae el hombre igual. mente, común denominador en que se ajustan. En esta sociedad se insinúa poco a poco su tantico de desvergüenza, ambiente que Graciela aprovecha, guiada por su instinto, para admitir o pernitirse ciertos atrevimientos. Los chicos no parecen conceder importancia a esto; pero en ella esta conducta va aguzándose $y$ desequilibrando un poco el temperamento.

Y cargado ya así el ambiente, aparezco yo. Me siento atraído a ella irresistiblemente (aunque te rías de mí), porque tiene la costumbre, en los restaurantes, en los cafés, en los casinos, de descalzarse un pie con otro por debajo de la mesa. ("Descalzando un pie con otro", motivo de los romances de Píramo y Tisbe. ¿Te acuerdas?) Adivino en un abrir y cerrar de ojos a la hembra incipiente. Sospecho la temperatura de 
irritación estéril a que sus amigos la han llevado. Me dejo fascinar; admito la compañía - al principio insoportable y poco a poco tolerada con mayor paciencia- de los muchachos, a cambio de merecer el amor de la muchacha... iY ya estoy perdido!

$Y$ ya estoy perdido por la sencilla razón de que todo, a mi al. rededor, facilita el deslizamiento. Aquellos hermanos pecadores no se burlan de mí, al contrario. Me rodean de una atmósfera de deferencia: parecen confabularse en mi ayuda. $Y$ es que soy su asunto de lujo, su gran acontecimiento sensual que alimenta sus secretos y sus confidencias. Graciela, turbada y, a pesar de todo, algo indecisa y paralizada a presencia mía, parece absorber en silencio las emanaciones que yo le mando, va descubriendo que apagan - exactamente- una sed a la que ella no sabia dar nombre; se deslumbra y tiembla en un silencio arrebatado que acaba por enamorarme y enloquecerme. $Y$ luego, a solas con sus amiguitos, aquello se vuelve una orquesta de revelaciones, de descubrimientos, de confesiones y recuerdos, que ellos a su vez apuran desde su apetito desorientado. No sé ya quién va a disfrutar más de esta expe. riencia amorosa: si yo cuando al fin la haga mujer, o ella y ellos cuando lo comenten, lo evoquen, lo imaginen, lo sazonen de fantasía difusa.

Me temo que la preparación de mi historia te interese más que el desenlace, $y$ voy a abreviar. Mi solicitación amorosa no tuvo de pronto más efecto que caldear, por decirlo así, la atmósfera de cuarto cerrado, de estufa, en que vivian Graciela y sus amigos. Pero el efecto final fue de tal manera desviado, y por lo mismo cómico, que casi acaba en chascarrillo.

Hoy sabemos bien, gracias sobre todo a las grandes novelas contemporáneas, que lo cortés no quita lo valiente, y que así como hay mujeres que cazan a pluma y a pelo, así también estos sujetos indefinidos que venían a ser el coro de Graciela stielen, aunque sea de pasada y sin concederle honores de primer premio, aceptar, a modo de accesit, alguna aventura común y corriente con las mujeres.

$Y$ verás lo que sucedió. Era un tal Armando. Guapo, aunque me pese y, sobre todo, "dotado de ojos" y con maneras cautivadoras. Poco a poco, se desprendió del coro anónimo de muchachos y dio unos pasos hacia Graciela. Quiero decir que empezó a participar más intimamente en sus dudas y en sus tentaciones. De modo que yo, sin saberlo, conforme despertaba a Graciela y trataba de conducirla por la vía derecha, resulta que la acercaba a Armando.

$Y$ como, al fin y a la postre, mi estrategia era una estrategia mas. culina, como llevaba su paso medido y hasta cierto cuidadoso recato 
para no romper de repente ese delicado cristal del rubor y de los pu. dores, me quedé atrás. Armando, que procedía por otro camino, que por llevar la marca de los no peligrosos o no comprometedores, se metía a deshoras en la casa, se hacía servir por la cocinera, tuteaba a la criada y hasta empujaba la puerta de la alcoba, sencillamente me ganó por la mano.

- ¿Contigo? - dijo Graciela entre burlona y escandalizada.

- Conmigo, sí-dijo Armando. Conmigo no tiene importancia. Es como si fuera tu hermana.

¿Necesito decirte más? ¿Ves desde allá mi cara de futuro amante burlado? Desde entonces, Carlos, les tengo a estos indefinidos más miedo que al Ogro. No, no podemos con ellos. Usamos armas desiguales. Nos. otros disponemos de un solo recurso, un solo campo de operaciones, una sola espada. Ellos, como el Samurai, tienen dos espadas.

$Y$ aunque te parezca un contrasentido y una blasfemia, me atrevo a decirte al oído que ellos parecen contar con la complicidad de la madre naturaleza, esta Lena, esta Celestina.

Te abraza tu amigo

Roberto Montes. 